\title{
Italian Multicenter Study on Accuracy of 18F-FDG PET/CT in Assessing Bone Marrow Involvement in Pediatric Hodgkin Lymphoma
}

DOI:

10.1016/j.clml.2018.04.002

\section{Document Version}

Accepted author manuscript

Link to publication record in Manchester Research Explorer

Citation for published version (APA):

Cistaro, A., Cassalia, L., Ferrara, C., Quartuccio, N., Evangelista, L., Bianchi, M., Fagioli, F., Bisi, G., Baldari, S., Zanella, A., Pillon, M., Zucchetta, P., Burei, M., Sala, A., Guerra, L., Guglielmo, P., Burnelli, R., Panareo, S.,

Scalorbi, F., ... Rubini, G. (2018). Italian Multicenter Study on Accuracy of ${ }^{\text {F-FDG PET/CT in Assessing Bone }}$ Marrow Involvement in Pediatric Hodgkin Lymphoma. Clinical Lymphoma, Myeloma and Leukemia, 18(6), e267e273. https://doi.org/10.1016/j.clml.2018.04.002

Published in:

Clinical Lymphoma, Myeloma and Leukemia

\section{Citing this paper}

Please note that where the full-text provided on Manchester Research Explorer is the Author Accepted Manuscript or Proof version this may differ from the final Published version. If citing, it is advised that you check and use the publisher's definitive version.

\section{General rights}

Copyright and moral rights for the publications made accessible in the Research Explorer are retained by the authors and/or other copyright owners and it is a condition of accessing publications that users recognise and abide by the legal requirements associated with these rights.

\section{Takedown policy}

If you believe that this document breaches copyright please refer to the University of Manchester's Takedown Procedures [http://man.ac.uk/04Y6Bo] or contact uml.scholarlycommunications@manchester.ac.uk providing relevant details, so we can investigate your claim.

\section{OPEN ACCESS}




\section{Accepted Manuscript}

Italian multicenter study on accuracy of 18F-FDG PET/CT in assessing bone marrow involvement in pediatric Hodgkin's Lymphoma

A. Cistaro, L. Cassalia, C. Ferrara, N. Quartuccio, L. Evangelista, M. Bianchi, F. Fagioli, G. Bisi, S. Baldari, A. Zanella, M. Pillon, P. Zucchetta, M. Burei, A. Sala, L.

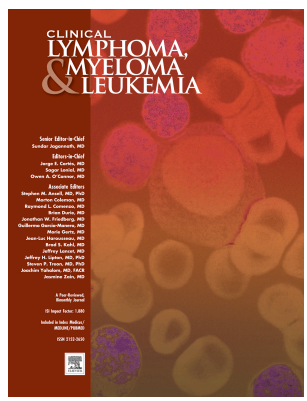
Guerra, P. Guglielmo, R. Burnelli, S. Panareo, F. Scalorbi, I. Rambaldi, A. Piccardo, A. Garaventa, D. Familiari, M.C. Fornito, E. Lopci, M. Mascarin, C. Altini, C. Ferrari, T. Perillo, N. Santoro, E. Borsatti, G. Rubini

PII: S2152-2650(18)30011-9

DOI: 10.1016/j.clml.2018.04.002

Reference: CLML 1095

To appear in: Clinical Lymphoma, Myeloma and Leukemia

Received Date: 5 January 2018

Revised Date: 15 March 2018

Accepted Date: 11 April 2018

Please cite this article as: Cistaro A, Cassalia L, Ferrara C, Quartuccio N, Evangelista L, Bianchi M, Fagioli F, Bisi G, Baldari S, Zanella A, Pillon M, Zucchetta P, Burei M, Sala A, Guerra L, Guglielmo P, Burnelli R, Panareo S, Scalorbi F, Rambaldi I, Piccardo A, Garaventa A, Familiari D, Fornito M, Lopci E, Mascarin M, Altini C, Ferrari C, Perillo T, Santoro N, Borsatti E, Rubini G, Italian multicenter study on accuracy of 18F-FDG PET/CT in assessing bone marrow involvement in pediatric Hodgkin's Lymphoma, Clinical Lymphoma, Myeloma and Leukemia (2018), doi: 10.1016/j.clml.2018.04.002.

This is a PDF file of an unedited manuscript that has been accepted for publication. As a service to our customers we are providing this early version of the manuscript. The manuscript will undergo copyediting, typesetting, and review of the resulting proof before it is published in its final form. Please note that during the production process errors may be discovered which could affect the content, and all legal disclaimers that apply to the journal pertain. 


\section{Italian multicenter study on accuracy of 18F-FDG PET/CT in assessing bone marrow involvement in pediatric Hodgkin's Lymphoma}

A. Cistaro ${ }^{1,2}$, L. Cassalia ${ }^{1}$, C.Ferrara ${ }^{3}$, N.Quartuccio ${ }^{4}$, L.Evangelista ${ }^{5}$, M.Bianchi ${ }^{6}$, F. Fagioli $^{6,7}$, G.Bisi ${ }^{8}$, S. Baldari ${ }^{9}$, A. Zanella $^{10}$, M.Pillon ${ }^{11}$, P. Zucchetta ${ }^{10}$, M.Burei ${ }^{10}$, A. Sala ${ }^{12}$, L.Guerra ${ }^{13}$, P.Guglielmo ${ }^{13}$, R.Burnelli ${ }^{14}$, S. Panareo ${ }^{15}$, F. Scalorbi $^{16}$, I. Rambaldi ${ }^{15}$, A. Piccardo ${ }^{17}$, A. Garaventa $^{18}$, D. Familiari ${ }^{19}$, MC. Fornito ${ }^{19}$, E Lopci $^{20}$, M. Mascarin ${ }^{21}$, C. Altini ${ }^{22}$, C. Ferrari ${ }^{22}$, T. Perillo $^{23}$, N. Santoro ${ }^{23}$, E. Borsatti ${ }^{24}$, G. Rubini ${ }^{22}$

Abbreviated title: Accuracy of 18F-FDG PET/CT in assessing bone marrow involvement in pediatric Hodgkin's Lymphoma

1 Positron Emission Tomography Centre IRMET S.p.A., Affidea, Turin, Italy

2 Chief of PET Pediatric Study Group of Italian Association of Nuclear Medicine AIMN, Italy

3 Nuclear Medicine Unit, Umberto I Hospital, Siracusa, Italy

4 Wolfson Molecular Imaging Centre, The University of Manchester, Manchester

5 Nuclear Medicineand Molecular Imaging Unit, Istituto Oncologico Veneto IOV-IRCCS, Padova, Italy

6 Pediatric Onco-Hematology and Stem Cell Transplant Division, City of Health and Science, Regina Margherita Children's Hospital, Turin, Italy

7 Chief of Italian Pediatric Oncology and Hematology Association AIEOP

8 Division of Nuclear Medicine, Azienda Ospedaliera Universitaria, Città della Salute e della Scienza, Turin, Italy

9 Nuclear Medicine Unit, Department of Biomedical Sciences and of Mophologic and Functional Images, University of Messina, Italy

10 Nuclear Medicine Service, Department of Medicine (DIMED), University Hospital, Padua, Italy

11 Department of Child and Woman Health, Oncology Hematology Division, University-Hospital of Padua, Padua, Italy

12 Maria Letizia Verga Center, MBBM Foundation - San Gerardo Hospital

13 Nuclear Medicine Unit, San Gerardo Hospital, Monza, Italy

14 Oncoematologia Pediatrica, Azienda Ospedaliera Universitaria, Ospedale Sant'Anna, Ferrara, Italy

15 Unit of Nuclear Medicine, Department of Diagnostic Imaging, S. Anna University Hospital, Ferrara, Italy

16 Nuclear Medicine Unit, University of Bologna, Italy

17 Nuclear Medicine Unit, Department of Diagnostic Imaging, E.O.Galliera Hospital, Genoa, Italy

18 Dipartimento di Ematologia e Oncologia Pediatrica Istituto G. Gaslini, Genova, Italy

19 Nuclear Medicine Department and PET/CT Center, ARNAS Garibaldi-Nesima, Catania, Italy

20 Department of Nuclear Medicine, Humanitas Research Hospital, Rozzano (Milano), Italy

21 S.S. Radioterapia Pediatrica e Area Giovani, IRCCS, Centro di Riferimento Oncologico Aviano, Pordenone, Italy

22 Nuclear Medicine Unit, University of Bari, Bari, Italy

23 Pediatric Hematology-Oncology Division, Department of Pediatrics, University of Bari, Bari, Italy

24 Nuclear Medicine Unit, IRCCS National Cancer Institute (CRO), Aviano, PN, Italy

\section{Corresponding Author:}

Angelina Cistaro, MD, Ph.

PositronEmissionTomography Centre IRMET, Affidea,

V. O. Vigliani 89 , Turin 10136, Italy.

Tel +390113160158; Fax +390113160828

e-mail: angelina.cistaro@affidea.it, angelacistaro@libero.it

Words of manuscript: 3021

The authors disclosure of any personal or financial support or author involvement with organization(s) with financial interest in the subject matter - or any actual or potential conflict of interest. 


\section{MICROABSTRACT}

This study investigated the utility of F-18-fluoro-2-deoxy-D-glucose (18F-FDG) positron emission tomography/computed tomography (PET/CT) in assessing bone marrow involvement (BMI) compared to bone marrow biopsy (BMB) in newly diagnosed pediatric Hodgkin's lymphoma (HL). 18F-FDG PET/CT shows high diagnostic performance in evaluating $\mathrm{BMI}$ in pediatric $\mathrm{HL}$. BMB should be ideally reserved for patients with 18F-FDG PET/CT presenting doubtful bone marrow findings.

\section{ABSTRACT:}

Introduction: This study investigated the utility of F-18-fluoro-2-deoxy-D-glucose (18F-FDG) positron emission tomography/computed tomography (PET/CT) in assessing bone marrow involvement (BMI) compared to bone marrow biopsy (BMB) in newly diagnosed pediatric Hodgkin's lymphoma (HL).

Materials and methods: 224 pediatric patients with $\mathrm{HL}$ underwent 18F-FDG PET/CT at staging. BMB or follow-up imaging were used as standard of reference for the evaluation of BMI.

Results: 18F-FDG PET/CT was negative for BMI in 193 cases. 16/193 patients were originally reported as doubtful, later interpreted as negative for $\mathrm{BMI}$, being negative at imaging follow-up and BMB; at BMB, 1/16 (6.25\%) patients had BMI. 192/193 (99,48\%) patients had negative BMB. Thus, 18F-FDG PET/CT was true negative in 192 patients and false negative in 1 patient for BMI.

Conclusions: 18F-FDG PET/CT shows high diagnostic performance in the evaluation of BMI in pediatric HL. $\mathrm{BMB}$ should be ideally reserved for patients with 18F-FDG PET/CT presenting doubtful bone marrow findings.

\section{INTRODUCTION}

Lymphoma is the third most common malignancy in the pediatric population (after leukemia and malignant brain tumors), comprising nearly $15 \%$ of childhood malignancies (53\% Hodgkin Lymphoma [HL] and $47 \%$ non-Hodgkin Lymphoma [NHL]) (1). Classic HL accounts for more than $85 \%$ of cases, whereas nodular lymphocyte-predominant $\mathrm{HL}$ is a less common subtype of $\mathrm{HL}$. The 5 -year survival rate is $95 \%$ for $\mathrm{HL}(2,3)$. Once a lymphoma has been diagnosed, the extension of disease has to be assessed $(4,5)$. HL is typically staged according to the Ann Arbor Staging Classification $(6,7)$, which was updated by the Cotswolds report in 1989 (8). Therapeutic options, such as chemotherapy and/or radiotherapy, depend on the stage of disease at the time of diagnosis, being different in patients with localized stage from those with an advanced/disseminated disease (9-11).

Detection of lymphomatous bone marrow involvement (BMI), which accounts for $10 \%$ of pediatric HL cases, is clinically relevant because its presence can upstage the disease to stage IV and modify planning treatment (11-16).

In clinical/radiological stage IA or IIA disease the incidence of BMI has been reported to be even lower or close to $0 \%(17,18)$. Due to the low incidence of $\mathrm{BMI}$ in early stages, the Cotswolds report recommends to restrict $\mathrm{BMB}$ to adult patients with computed tomography (CT) to stage III/IV disease or stage II disease with adverse unfavorable factors $(8,19)$.

According to the latest guidelines issued by the Italian Association of Pediatric Onco-hematology (AIEOP), $B M B$ should be preferentially done in symptomatic patients (class B) or those at stage $\geq$ III. However, in Italy, $B M B$ is heterogeneously and commonly performed is paediatric patients with $\mathrm{HL}$. 
Nowadays, BMB remains the gold standard to determine bone marrow status but it has poor sensitivity (50\%) for two main reasons: 1 ) the sample size may be small; 2 ) sometimes the $B M I$ is focal $(20,21)$. The main advantage of $B M B$ is the acquisition of histological material. Moreover, a positive $B M B$ is considered as a definitive proof of BMI. On the other hand, the major disadvantage of BMB is its invasiveness; it is a stressful and painful procedure, despite the use of local anesthesia.

18F-FDG-PET/CT has become an established method for lymphoma staging, and it may be potentially a noninvasive alternative or complementary method to BMB (22). A major advantage of $18 \mathrm{~F}-\mathrm{FDG}$ PET/CT is that it allows visualization of the entire marrow. However, the clinical value of PET/CT for the evaluation of the BMI in lymphoma is still under debate and investigation. Whilst there is a large body of evidence supporting the use of PET/CT for the evaluation of BMI in adults (23), few data are available about the diagnostic utility of $\mathrm{PET} / \mathrm{CT}$ in relation to pediatric lymphoma for BM assessment (5).

The aim of the current multicentric italian study is to define the utility of 18F-FDG PET/CT to identify BMI compared to $\mathrm{BMB}$, in newly diagnosed $\mathrm{HL}$ pediatric patients.

\section{MATERIALS AND METHODS}

A total of 224 pediatric patients (mean age 14 years; range 4-18 years), with a initial diagnosis of $\mathrm{HL}$, were retrospectively enrolled in this study across 10 Italian Nuclear Medicine departments: Padua ( $n=65 ; 2$ centers), Turin ( $n=62 ; 2$ centers), Monza ( $n=37)$, Bari $(n=27)$, Genoa $(n=21)$, Bologna $(n=7)$; Ferrara $(n=3)$ and Catania $(n=2)$ (Table 1).

All patients underwent physical examination, routine blood parameters, contrast-enhanced CT scan of the neck/chest/abdomen, BMB and 18F-FDG PET/CT scan as part of the routine protocol for the initial staging. The Ann Arbor stage was determined without considering bone marrow uptake on the 18F-FDG PET/CT study.

The inclusion criteria were: 1) biopsy confirmation of $\mathrm{HL}$; 2) availability of BMB and baseline 18F-FDG $\mathrm{PET} / \mathrm{CT}$ results; 3 ) age $<=18$ years; 4) availability of clinical and instrumental follow-up for at least 12 months.

Exclusion criteria were: 1) prior known and treated lymphoma; 2) presence of other concomitant malignancy; 3) previous chemo- or corticosteroid therapy; 4) interval between 18F-FDG PET/CT scan and BMB longer than 15 days.

The institutional review board granted a waiver for the patient informed consent due to the retrospective nature of this study.

\section{F-FDG PET/CT acquisition}

All 18F-FDG PET/CT baseline scans were performed as whole-body scans (from the base of the skull to midthigh) after a 6-hr fasting period. Patients underwent blood glucose tests prior to administering 18F-FDG to ensure suitably low levels, received adequate pre-hydration, remained recumbent and silent in warm room to ensure fewer artifacts and to minimize 18F-FDG uptake in muscles and brown fat activation.

PET/CT studies were obtained on the following PET/CT devices: Gemini TF64 (Philips), Gemini GXL (Philips), Gemini TF16 (Philips), Discovery LS (GE Healthcare), and Biograph TP16 (Siemens) according to the local 
institutional scanning protocols. The emission data were acquired for 2-5 min per bed position (based on the available scan system) starting 60-90 min after intravenous injection of the body weight-adapted FDG dosage recommended according to the manufacturer guidelines for each scan model. Quality control procedures were carried out at regular intervals for all devices with strict adherence to local protocols, manufacturer guidelines, and EANM guidelines.

The low dose CT components of the PET/CT were used for both co-localization and attenuation correction of the PET emission data. Coronal, sagittal, and transversal PET/CT projections were reconstructed by iterative methods and analyzed using the manufacturers' software.

\section{F-FDG PET/CT interpretation}

At each institution, nuclear medicine physicians reviewed independently PET/CT images, blinded to the BMB results, with particular attention to the bone marrow.

18F-FDG PET/CT findings were considered positive for BMI in the presence of:

(-) isolated/multiple focal uptake in the bone marrow that could not be explained by benign findings on the underlying CT images or history (e.g. fractures);

(-) diffuse heterogeneous BMI with or without sites of intense focal uptake superior to liver or spleen background (in accordance with the Deauville Criteria (24)

In contrast 18F-FDG PET/CT was interpreted negative for BMI in the presence of:

(-) diffuse homogenous marrow involvement without sites of intense focal involvement [being reported that diffuse intense uptake is significantly related to anemia or inflammatory process (25-27)]

In doubtful cases images, a second opinion was requested to the leading centre of the multicenter study and the images were reviewed by an experienced nuclear medicine physician (13 years' experience in pediatric PET/CT).

\section{Bone marrow biopsy}

Unilateral posterior iliac crest biopsy and marrow aspirate were pretherapeutically carried out according to AIEOP guidelines.

$\mathrm{BMB}$ were evaluated by experienced hematopathologists in each hospital; results were obtained from the individual reports and were not reviewed thereafter. BMB material was routinely formalin-fixed and paraffin embedded and subsequently evaluated morphologically on the basis of hematoxilin-eosin and Giemsa stains. As a rule, pan- $T$ (at least CD3 and CD5), pan B (at least CD19 and CD20), CD30 and CD15 stains were performed in all cases.

In cases negative on $\mathrm{BMB}$ and positive on $\mathrm{PET} / \mathrm{CT}$ imaging for $\mathrm{BMI}$, the final diagnosis was established by follow-up imaging (up to 12 months): MRI with dedicated T1-weighted, T2-weighted and fat-suppressed T2weighted sequences, bone scan and/or CT using bone window. In case of unavailability of imaging followup, clinical data were retrieved. 


\section{Statistical Analysis}

Patients were categorized according to the absence or presence of BMI evaluated with BMB and 18F-FDG PET/CT results. For the whole patient cohort, positive and negative predictive values (PPV and NPV, respectively), sensitivity, specificity and accuracy were calculated separately for BMB and 18F-FDG PET/CT. Agreement between the 18F-FDG PET/CT and BMB was assessed using Kohen's k computation .

\section{RESULTS}

\section{Patient characteristics}

Two hundred twenty-four patients were analyzed. 10 (4.4\%) patients were at stage I, $99(44.2 \%)$ at stage II, $65(29 \%)$ at stage III and $50(22.4 \%)$ at stage IV. Moreover, $155(69 \%)$ patients had a nodular sclerosis, 24 $(11 \%)$ a mixed cellularity, $4(1.7 \%)$ a lymphocytic predominance, $19(8.4 \%)$ a classical and $22(9.9 \%)$ a nonclassical lymphocytic predominance variant (Table 1).

\section{Diagnostic Performance of 18F-FDG PET/CT}

18F-FDG PET/CT was reported as negative for BMI in 193 cases. Sixteen out of 193 patients showed a diffuse FDG uptake in the bone marrow, and therefore originally reported as doubtful, later interpreted as negative for $\mathrm{BMI}$, being negative at imaging follow-up and BMB; at BMB, 1/16 (6.25\%) patients had a BMI. 192/193 $(99,48 \%)$ patients had a negative BMB. Thus, 18F-FDG PET/CT was true negative in 192 patients and false negative in 1 patient for BMI.

18F-FDG PET/CT was reported as positive for BMI in 31 patients. BMB was positive in $9 / 31$ patients and negative in 22/31. Subsequent CT and/or MR and/or bone scan confirmed PET/CT findings in 16 of these 22 patients.

The residual 6 patients were considered as false positive: $4 / 6$ due to anaemia ( $\mathrm{Hb}$ levels $<9 \mathrm{~g} / \mathrm{dl}$ ) and 2/6 for inflammation (ESR $>20 \mathrm{~mm} / \mathrm{h}$ and $\mathrm{CPR}>200 \mathrm{mg} / \mathrm{L}$ ). The agreement between PET/CT and BMB was considered fair; the resulting $\mathrm{K}$ cohen for the two techniques was 0.4 ( $p<0.001$; Table 2$)$.

Sensitivity, specificity, NPV and PPV of 18F-FDG PET/CT for the evaluation of BMI were 96\% (Cl 95\%: 89100\%), 97\% (Cl 95\%: 95-99\%), 99.5\% (Cl 95\%: 98-100\%) and 80.6\% (Cl 95\%: 65.5-96\%), respectively. On the contrary, the sensitivity, specificity, NPV and PPV of BMB were 38\% (CI 95\%: 20-57\%), 100\%, 92.5\% (CI 95\%: $89-96 \%$ ) and $100 \%$, respectively.

The distribution of stage disease and 18F-FDG PET/CT results are presented in Table 3. As illustrated, all 6 patients with false positive PET/CT results were at stage IIIA/B or IVA. Conversely, patients with true positive $\mathrm{PET} / \mathrm{CT}$ results, had heterogeneously stage of disease (8 stage III-IV vs 8 stage II; $68 \%$ vs. $32 \%$, respectively).

Out of 16 patients with a false positive BMB result, 8 subjects at stage IIA/IIB were truly positive at 18F-FDG $\mathrm{PET} / \mathrm{CT}$ for $\mathrm{BMI}$, thus changing the treatment management. In the remnant 8 patients at stage IIIA/B ( $n=5$ ) and IVA/B $(n=3)$, no change in management was reported. Conversely, 18F-FDG PET/CT was falsely positive in 6 patients at stage IIIB/IVA. All false positive PET cases (1: stage III and 5: stage IV) had negative imaging follow-up and negative BOM.

Only 1 falsely negative patient (stage IIIA), was reported on PET/CT, and did not lead to alteration of treatment planning. The false negative PET case resulted to be positive on both BOM and CT imaging 
One limitation of the study may be that images interpretation was not centralized, however the authors consistently used qualitative interpretation of imaging, evaluating the cases as positive or negative according to the Deauville Criteria; in doubtful cases, a second opinion was requested to the leading centre of the multicenter study and the PET/CT images were reviewed by an experienced nuclear medicine physician (13 years' experience in pediatric $\mathrm{PET} / \mathrm{CT}$ ).

\section{DISCUSSION}

The present manuscript reports data about the performance of BMB and 18F-FDG PET/CT for the identification of BMI in a series of 224 lymphoma pediatric patients.

The bone marrow is an important anatomical site where lymphomatous cells can reside. Detection of Iymphomatous BMI may be clinically relevant from several perspectives. First, identifying lymphomatous cells in the bone marrow may aid in the diagnosis of lymphoma. Second, bone marrow assessment is a crucial part of the Ann Arbor system. Third, the presence of BMI may change the choice of therapy. Fourth, knowing all sites of lymphomatous involvement, including bone marrow sites, allows monitoring the effects of therapy.

$\mathrm{BMB}$ is an invasive procedure that provides histologic examination of just a small bone marrow sample, whereas 18F-FDG PET/CT is a non-invasive method that lacks histologic material but allows visualization of the entire marrow (28).

The distribution of 18F-FDG throughout the skeleton follows that of the red marrow $(29,30)$, which changes during normal aging (31). Under normal conditions the bone marrow shows homogeneously low uptake of 18F-FDG, with the bone marrow appearing less intense than the liver. However, as para-physiological variants, increased 18F-FDG activity in the bone marrow can be observed in patients undergoing, or soon after the end, chemotherapy (usually within one month), patients with hyperplasia and hematopoietic stimulation from anemia and patients who received granulocyte colony-stimulating factor (CSF), hematopoietic growth factor, or erythropoietin (32).

In our pediatric patient population, we found that 18 F-FDG PET/CT was negative for BMI in $86 \%$ of patients. Based on the gold standard, 18F-FDG PET/CT resulted TN in 192 patients, FN in 1 patient, TP in 25 and FP in 6 subjects. However, this latter finding was more frequent in patients at advanced stages (IIIA/B and IVA). On the other hand, we found that BMB showed a high number of FN findings, thus reporting a lower sensitivity than 18F-FDG PET/CT imaging ( $38 \%$ vs $96 \%$, respectively). Nevertheless, BMB did not show any FP results.

To date in literature, there are a lot of data about the role of 18F-FDG PET/CT in the evaluation of BMI in adult patients with $\mathrm{HL}$, while data relative to pediatric lymphoma remain limited.

In adults, 18F-FDG PET/CT can be proposed as a very sensitive method for the detection of BMI that may overcome the diagnostic yield of BMB (33-35). Furthermore, Adams et al reported that, in a series of 235 adult patients, about $70 \%$ of them experienced procedure-related pain, reporting severe pain in one-third of these patients (36). Nevertheless, at least until recently, there was still a lot of variability in the use or the omission of BMB in Hodgkin lymphoma patients in routine clinical practice (37).

In pediatric population, some retrospective studies have demonstrated that $18 \mathrm{~F}-\mathrm{FDG}$ PET/CT is superior 
than conventional imaging modalities (i.e. CT, ultrasound, magnetic resonance imaging (MRI) or bone scintigraphy) in the primary staging of lesions, both in Hodgkin's and non-Hodgkin's disease (38-41; Table 4). In the initial staging of pediatric lymphoma, 18F-FDG PET/CT findings are usually consistent with CT scan findings. Although its specificity is decreased when the disease is located in anatomical sites where physiologic 18F-FDG uptake takes place (42-44); in 9.4-22.6\% of the cases, 18F-FDG PET/CT may show abnormalities that are not displayed by other imaging methods and is useful during disease staging and treatment planning $(45,46)$. Overall, all studies were performed by considering all site of lesions (nodal and extra-nodal) without a specific information of BMI. Additionally, our study showed that 18F-FDG PET/CT was more accurate also in the detection of BMI than BMB (sensitivity: $96 \%$ vs $38 \%$, respectively).

Similar results were reported by Purz et al. (47) who compared the results from BMB and 18F-FDG PET/CT for the diagnosis of BMI in 175 pediatrics patients with $\mathrm{HL}$ stage greater than IIA. The authors concluded that 18F-FDG PET may safely replace BMB in routine staging procedure in pediatric $\mathrm{HL}$, particularly in patients with a focal BMI. Salaun et al. (27) retrospectively analyzed 106 pediatric and adult patients who underwent 18F-FDG PET/CT for initial staging of $\mathrm{HL}$ and concluded that an increased bone marrow uptake could more likely be due to inflammation than BMI and only the presence of bone foci should be interpreted as bone involvement on visual 18F-FDG PET/CT evaluation. In the present study, we considered a diffuse bone marrow involvement with or without the presence of the focal foci. The interpretation of PET/CT was made by using the Deauville Criteria. These criteria are mainly employed for the evaluation of the interim response to therapy (24), however they can be applied also in the initial staging of disease.

In a recent study presented at the Annual Congress of the Society of Nuclear Medicine, Chen et al. (48) reported that in 75 pediatric patients with diagnosed NHL, 18F-FDG PET/CT demonstrated a higher sensitivity and specificity than BMB (94\% and $98 \%$ vs. $55 \%$ and $100 \%$, respectively for 18 F-FDG PET/CT and $\mathrm{BMB})$.

In our analysis, we found that 6 patients at stage II, falsely assessed by BMB, were reclassified as stage IV after the inclusion of 18F-FDG PET/CT in the diagnostic algorithm, changing both clinical stage and therapeutic management. Differently, false positive findings at 18F-FDG PET/CT did not change neither stage of disease nor therapeutic management. Furthermore, on the basis of these results, all 31 patients in our series with BMI would be classified as having advanced stage disease. Thus, the identification of BMI by $\mathrm{BMB}$ would not have altered treatment recommendations for any of these patients. Of interest, BMB-based lymphomatous bone marrow involvement has not been proven to be a major adverse predictor of outcome in Hodgkin lymphoma. In the cohort on the development of the International Prognostic Score (IPS) in advanced stage Hodgkin lymphoma, progression-free survival (PFS) and overall survival (OS) in 614 patients with BMB-proven BMI (60\% and 70\% respectively) were not significantly different from those in 1351 patients without $\mathrm{BMI}$ according to $\mathrm{BMB}$ ( $61 \%$ and $74 \%$ respectively) (4). This findings indicate that omission of BMB would not result in a major decline in prognostic power of the IPS in patients with advanced stage disease (49). In early stage disease, the incidence of BMI is extremely low, and the prognostic value of BMB in this subpopulation has therefore not been well documented. However our study shows that 18F-FDG $\mathrm{PET} / \mathrm{CT}$ is superior to $\mathrm{BMB}$ in the identification of this subgroup of patients, changing the stage and patient management. An interest finding of our study is the modest specificity of +BM PET compared to bone marrow biopsy; this fact could reflect an highly heterogenous environment in the BM indicating that a single site biopsy is not perfectly adequate in depicting the heterogeneous characteristics of the bone marrow in pediatric $\mathrm{HL}$.

However, the present study has some limitations. Firstly, the retrospective collection of data can represent a 
limit. Secondly, all collected cases were considered by a multicenter analysis; however the interpretation of 18F-FDG PET/CT scans was made by a visual analysis rather than semiquantitative one. Lastly, since imagebased follow-up was carried out separetely in each centre rather than in a single centre, variable experience of examining physicians and different imaging protocols and facilities my have lead to different grades of reliability and accuracy of the reference standard.

\section{CONCLUSIONS}

We reported data on 18F-FDG PET/CT and BMB performance in the diagnosis of BMI in a series of 224 pediatric patients with $\mathrm{HL}$. Our results show that 18F-FDG PET/CT has a high diagnostic power for the evaluation of $\mathrm{BMI}$ involvement in $\mathrm{HL}$ supporting the concept that BMB should not be systematically performed in all the patients, but may be reserved exclusively for patients with doubtful 18-FDG bone marrow findings.

\section{REFERENCES}

1 Uslu L, Donig J, Link M, Rosenberg J, Quon A, Daldrup-Link HE. Value of 18F-FDG PET and PET/CT for evaluation of pediatric malignancies. J Nucl Med. 2015;56:274-86.

2 Ries LAG, Smith MA, Gurney JG, et al., eds. Cancer Incidence and Survival Among Children and Adolescents: United States SEER Program 1975-1995. Bethesda, MD: National Cancer Institute; 1999. NIH publication 99-4649.

3 Ward E, DeSantis C, Robbins A, Kohler B, Jemal A. Childhood and adolescent cancer statistics, 2014. CA Cancer J Clin. 2014;64:83-103

4 Favier O, Heutte N, Stamatoullas-Bastard A, Carde P, Van't Veer MB, Aleman BM, et al. Survival after Hodgkin lymphoma: causes of death and excess mortality in patients treated in 8 consecutive trials. Cancer. 2009;115:1680-91.

5 Agrawal K, Mittal BR, Bansal D, Varma N, Srinivasan R, Trehan A, Manohar K, Kashyap R, Bhattacharya A, Marwaha RK. Role of F-18 FDG PET/CT in assessing bone marrow involvement in pediatric Hodgkin's lymphoma. Ann Nucl Med. 2013;27:146-51.

6 Simpson CD, Gao J, Fernandez CV, Yhap M, Price VE, Berman JN. Routine bone marrow examination in the initial evaluation of paediatric Hodgkin lymphoma: the Canadian perspective. Br J Haematol. 2008;141:8206.

7 Carbone PP, Kaplan HS, Musshoff K, Smithers DW, Tubiana M. Report of the Committee on Hodgkin's Disease Staging Classification. Cancer Res. 1971;31:1860-1.

8 Lister TA, Crowther D, Sutcliffe SB. Report of a committee convened to discuss the evaluation and staging of patients with Hodgkin's disease: Cotswolds meeting. J ClinOncol. 1989;7:1630-6.

9 Eghbali H, Raemaekers J, Carde P. EORTC Lymphoma Group. The EORTC strategy in the treatment of Hodgkin's lymphoma. Eur J Haematol Suppl. 2005;66:135-40. 
10 Connors JM. State-of-the-art therapeutics: Hodgkin's lymphoma. J ClinOncol. 2005;23:6400-8.

11 Diehl V, Fuchs M. Early, intermediate and advanced Hodgkin's lymphoma: modern treatment strategies. Ann Oncol. 2007;18:71-9.

12 Bartl, R., Frisch, B., Burkhardt, R., Huhn, D. \&Pappenberger, R. Assessment of bone marrow histology in Hodgkin's disease: correlation with clinical factors. Br J Haematol. 1982;51:345-360.

13 Doll, D.C., Ringenberg, Q.S., Anderson, S.P., Hewett, J.E. \&Yarbro, J.W. Bone marrow biopsy in the initial staging of Hodgkin's disease. Medical and Pediatric Oncology. 1989;17:1-5.

14 Spector, N., Nucci, M., Oliveira De Morais, J.C., Maiolino, A., Portugal, R.D., Costa, M.A. \&Pulcheri, W. Clinical factors predictive of bone marrow involvement in Hodgkin's disease. Leukaemia\& Lymphoma. 1997; 26:171-6.

15 Mahoney, D.H., Jr, Schreuders, L.C., Gresik, M.V. \& McClain, K.L. Role of staging bone marrow examination in children with Hodgkin disease. Medical and Pediatric Oncology. 1998;30,175-7.

16 Wang, J., Weiss, L.M., Chang, K.L., Slovak, M.L., Gaal, K., Forman, S.J. \& Arber, D.A. Diagnostic utility of bilateral bone marrow examination: significance of morphologic and ancillary technique study in malignancy. Cancer. 2002;94:1522-31.

17 Adams HJ, Nievelstein RA, Kwee TC Opportunities and limitations of bone marrow biopsy and bone marrow FDG-PET in lymphoma. Blood Rev. 2015;29:417-25.

18 Vassilakopoulos TP, Angelopoulou MK, Constantinou N, Karmiris T, Repoussis P, Roussou P, et al. Development and validation of a clinical prediction rule for bone marrow involvement in patients with Hodgkin lymphoma. Blood. 2005;105: 1875-80.

19 Howell SJ, Grey M, Chang J,Morgenstern GR, Cowan RA, Deakin DP, et al. The value of bone marrow examination in the staging of Hodgkin's lymphoma: a review of 955 cases seen in a regional cancer centre. Br J Haematol. 2002;119:408-11.

20 Brunning RD, Bloomfield CD, McKenna RW, Peterson L Bilateral trephine bone marrow biopsies in lymphoma and other neoplastic diseases. Ann Intern Med.1975;82:365-366.

21 Menon NC, Buchanan JG Bilateral trephine bone marrow biopsies in Hodgkin's and non-Hodgkin's lymphoma. Pathology. 1979;11:53-57.

22 Cortes-RomeraM, Sabate-LloberaA,Mercadal-Vilchez S, Climent-Esteller F, Serrano-Maestro A, GamezCenzano C, et al. Bone marrow evaluation in initial staging oflymphoma: 18F-FDG PET/CT versus bone marrow biopsy. ClinNucl Med. 2014;39:e46-52.

23 Chen-Liang TH, Martin-Santos T, Jerez A, Senent L, Orero MT, Remigia MJ et al.The role of bone marrow biopsy and FDG-PET/CT in identifying bone marrow infiltration in the initial diagnosis of high grade nonHodgkin B-cell lymphoma and Hodgkin lymphoma. Ac-curacy in a multicenter series of 372 patients. Am J Hematol. 2015;90:686-90.

24 Meignan M, Gallamini A, Haioun C. Report on the First International Workshop on Interim-PET-Scan in Hodgkin Lymphoma. Leuk Lymphoma. 2009; 50:1257-60. 
25 Hollinger EF, Alibazoglu H, Ali A, Green A, Lamonica G. Hematopoietic cytokine-mediated FDG uptake simulates the appearance of diffuse metastatic disease on whole-body PET im-aging. ClinNucl Med. 1998;23:93-98.

26 Rosenbaum SJ, Lind T, Antoch G, Bockisch A False-positive FDG PET uptake: the role of PET/CT. Eur Radiol. 2006;16:1054-65.

27 Salaun PY, Gastinne T, Bodet-Milin C, et al Analysis of 18F-FDG PET diffuse bone marrow uptake and splenic uptake in staging of Hodgkin's lymphoma: a reflection of disease infiltration or just inflammation? Eur J Nucl Med Mol Imaging.2009;36:1813-21.

28 Adams HJA, Nievelstein RAJ, Kwee TC. Opportunities and limitations of bone marrow biopsy and bone marrow FDG-PET in lymphoma. Blood Reviews 2015; 29:417-425

29 Fan C, Hernandez-Pampaloni M, Houseni M, ChamroonratW, Basu S, Kumar R, et al. Age-related changes in the metabolic activity and distribution of the red marrow asdemonstrated by 2-deoxy-2-[F-18]fluoro-Dglucose-positron emission tomography. Mol Imaging Biol. 2007;9:300-7.

30 Aras M, Dede F, Ones T, Inanir S, Erdil TY, Turoglu HT. Evaluation of physiologicalFDG uptake in the skeleton in adults: is it uniformly distributed? Rev Esp Med Nucl Imagen Mol. 2014;33:286-9.

31 Vande Berg BC, MalghemJ, Lecouvet FE, MaldagueB.Magnetic resonance imaging of the normal bone marrow. Skeletal Radiol. 1998;27:471-83.

32 Agool A, Glaudemans AW, Boersma HH, Dierckx RA, Vellenga E, Slart RH. Radionuclideimaging of bone marrow disorders. Eur J Nucl Med Mol Imaging. 2011;38:166-78.

33 Barrington SF, Mikhaeel NG, Kostakoglu L, Meignan M, Hutchings M, Mueller SP,et al. Role of imaging in the staging and response assessment of lymphoma: consensusof the International Conference on Malignant Lymphomas Imaging WorkingGroup. J ClinOncol. 2014;32:3048-58.

34 Cheson BD, Fisher RI, Barrington SF, Cavalli F, Schwartz LH, Lister TA. Recommendations for initial evaluation, staging, and response assessment of Hodgkinand non-Hodgkin lymphoma:J ClinOncol. 2014;32:3059-68.

35 Kobe C, Voltin C-A, Baues C, Fuchs M, Dietlein M, Engert A, Borchmann P, Drzezga A. Staging Hodgkin Lymphoma Using PET -Can We Safely Exclude Bone Marrow Involvement? J Nucl Med. 2017;58:565S.

36 Liden Y, Landgren O, Arner S, Sjolund KF, Johansson E. Procedure-related pain among adult patients with hematologic malignancies. ActaAnaesthesiol Scand. 2009;53:354-63.

37 Richardson SE, Sudak J, Warbey V, Ramsay A, McNamara CJ. Routine bone marrow biopsy is not necessary in the staging of patients with classical Hodgkin lymphoma in the 18F-fluoro-2-deoxyglucose positron emission tomography era. Leuk Lymphoma. 2012;53:381-5.

38 Kabickova E, Sumerauer D, Cumlivska E, Drahokoupilova E, Nekolna M, Chanova M, et al. Comparison of 18F-FDG-PET and standard procedures for the pretreatment staging of children and adolescents with Hodgkin's disease. Eur J Nucl Med Mol Imaging. 2006; 33:1025-1031.

39 Furth C, Denecke T, Steffen I, Ruf J, Voelker T, Misch D, et al. Correlative Imaging strategies im-plementing 
CT, MRI, and PET for staging of childhood Hodgkin disease. J Pediatr Hematol Oncol. 2006;28: 501-12.

40 Cheng G, Servaes S, Zhuang H. Value of (18)F-fluoro-2-deoxy-D-glucose positron emission tomography/computed tomography scan versus diagnostic contrast computed tomography in ini-tial staging of pediatric patients with lymphoma. Leuk Lymphoma. 2013; 54:737-42

41 London K, Cross S, Onikul E, Dalla-Pozza L, Howman-Giles R. 18F-FDG PET/CT in paediatric lymphoma: comparison with conventional imaging. Eur J Nucl Med Mol Imaging. 2011; 38:274-84.

42 Lopci E, Burnelli R, Guerra L, Cistaro A, Piccardo A, Zucchetta P, Derenzini E, Todesco A, Garaventa A, Schumacher F, Farruggia P, Buffardi S, Sala A, Casale F, Indolfi P, Biondi S, Pession A, Fanti S.Postchemotherapy PET evaluation correlates with patient outcome in paediatric Hodgkin's disease. Eur J Nucl Med Mol Imaging. 2011;38:1620-7.

43 Sioka C. The utility of FDG PET in diagnosis and follow-up of lymphoma in childhood. Eur J Pediatr. 2013;172:733-8.

44 DepasG,DeBarsyC,JerusalemG,HoyouxC, Dresse MF, Fassotte MF, PaquetN, FoidartJ,Rigo P, Hustinx R. 18F-FDG PET in children with lymphomas. Eur J Nucl Med Mol Imaging. 2005;32:31-38.

45 Miller E, Metser U, Avrahami G,Dvir R,Valdman D,Sira LB,Sayar D, Burstein Y, Toren A, Yaniv I, Even-Sapir E. Role of 18F-FDG PET/CT in staging and follow-up of lymphoma in pediatric and young adult patients. J Comput Assist Tomogr.2006;30:689-69.

46 Paulino AC, Margolin J, Dreyer Z, Teh BS, Chiang S. Impact of PET-CT on involved field radiotherapy design for pediatric Hodgkin lymphoma. Pediatr Blood Cancer. 2012;58:860-864.

47 Purz S, Mauz-Korholz C, Korholz D, Hasenclever D, Krausse A, Ruschke K, Stiefel M, Amthauer H, SchoberO,KranertWT, Weber WA, Haberkorn U, Hundsdorfer P, Ehlert K, Becker M, Rossler J, Kulozik AE, Sabri O, Kluge R. [18F] Fluorodeoxyglucose positron emission tomography for detection of bone marrow involvement in children and adolescents with Hodgkin's lymphoma. J ClinOncol. 2011;29:3523-28.

48 Chen S, Wang Y, He K, Wang H. 18F-FDG PET/CT for Detection of Bone Marrow Involvement in Children and Adolescents with Non-Hodgkin Lymphoma. J Nucl Med. 2017:58;640S.

49 Hasenclever D, Diehl V. A prognostic score for advanced Hodgkin's disease. InternationalPrognostic Factors Project on Advanced Hodgkin's Disease. N Engl J Med. 1998;339:1506-14.

\section{Legend:}

\section{Figure 1}

A-C: diffuse FDG bone marrow uptake pattern in the skeleton reported as doubtful bone marrow finding. The $B M B$ resulted to be negative.

D-F: focal FDG uptake interpreted as a FDG-avid bone marrow lesion. The BMB resulted concordant with the FDG finding. 


\begin{tabular}{|l|l|}
\hline Patient number & 224 \\
\hline Mean Age & 14 years (4-18) \\
\hline Histotype & 155 nodular sclerosis \\
\cline { 2 - 2 } & 24 mixed ceelularity \\
\cline { 2 - 2 } & 22 non-classical lymphocitic predominance variant \\
\cline { 2 - 2 } & 19 classical variant \\
\cline { 2 - 2 } & 4 lymphocitic variant \\
\hline \multirow{5}{*}{ Stage } & I: 10 \\
\cline { 2 - 2 } & II: 99 \\
\cline { 2 - 2 } & III: 65 \\
\cline { 2 - 2 } & IV: 50 \\
\hline
\end{tabular}

Table 1: patient demographics 
Table 2. Agreement between 18F-FDG PET/CT and bone marrow biopsy

\begin{tabular}{|l|l|l|l|}
\hline & $\begin{array}{l}\text { Negative } \\
\text { BMB }\end{array}$ & $\begin{array}{l}\text { Positive } \\
\text { BMB }\end{array}$ & Total \\
\hline Negative PET/CT & 192 & 1 & 193 \\
\hline Positive PET/CT & 22 & 9 & 31 \\
\hline Total & 214 & 10 & $\mathbf{2 2 4}$ \\
\hline
\end{tabular}

K agreement: $0.398(p<0.001)$ 
Table 3.Distribution of PET/CT results in accordance with clinical staging

\begin{tabular}{|l|l|l|l|l|l|l|l|l|l|}
\hline PET/CT & \multirow{2}{*}{$\begin{array}{l}\text { N } \\
\text { pts }\end{array}$} & \multicolumn{2}{|l|}{ Stage I } & \multicolumn{2}{l|}{ Stage II } & \multicolumn{2}{l|}{ Stage III } & \multicolumn{2}{l|}{ Stage IV } \\
\cline { 3 - 11 } & & $\begin{array}{l}\text { Stage } \\
\text { IA }\end{array}$ & $\begin{array}{l}\text { Stage } \\
\text { IB }\end{array}$ & $\begin{array}{l}\text { Stage } \\
\text { IIA }\end{array}$ & $\begin{array}{l}\text { Stage } \\
\text { IIB }\end{array}$ & $\begin{array}{l}\text { Stage } \\
\text { IIIA }\end{array}$ & $\begin{array}{l}\text { Stage } \\
\text { IIIB }\end{array}$ & $\begin{array}{l}\text { Stage } \\
\text { IVA }\end{array}$ & $\begin{array}{l}\text { Stage } \\
\text { IVB }\end{array}$ \\
\hline TP & 25 & & & 3 & 5 & 3 & 2 & 5 & 7 \\
\hline TN & 192 & 9 & 1 & 58 & 33 & 30 & 28 & 30 & 3 \\
\hline FP & 6 & & & & & & 1 & 5 & \\
\hline FN & 1 & & & & & 1 & & & \\
\hline Total & $\mathbf{2 2 4}$ & $\mathbf{1 0}$ & & $\mathbf{9 9}$ & $\mathbf{6 5}$ & $\mathbf{5 0}$ & \\
\hline
\end{tabular}


Table 4. Collection of published data about 18F-FDG PET/CT and $\mathrm{Cl}$ in initial staging of disease.

\begin{tabular}{|c|c|c|c|c|c|c|c|c|c|c|}
\hline \multirow[t]{2}{*}{ Authors } & \multirow{2}{*}{$\begin{array}{l}\text { Year } \\
\text { of } \\
\text { pub }\end{array}$} & \multirow{2}{*}{$\begin{array}{l}\text { Number } \\
\text { of } \\
\text { patients }\end{array}$} & \multicolumn{4}{|c|}{ FDG PET or PET/CT } & \multicolumn{4}{|c|}{ Conventional imaging } \\
\hline & & & Sensitivity & Specificity & NPV & PPV & Sensitivity & Specificity & NPV & PPV \\
\hline $\begin{array}{l}\text { Kabickova } \\
\text { et al (37) }\end{array}$ & 2006 & $\begin{array}{l}55 \\
\text { children } \\
\text { and } \\
\text { adolescent }\end{array}$ & $96.5 \%$ & $100 \%$ & - & - & $87.5 \%$ & $60 \%$ & - & - \\
\hline $\begin{array}{l}\text { Furth C, } \\
\text { et al (38) }\end{array}$ & 2006 & $\begin{array}{l}33 \\
\text { pediatrics }\end{array}$ & $84 \%$ & $95 \%$ & $94 \%$ & $87 \%$ & $74 \%$ & $96 \%$ & $91 \%$ & $88 \%$ \\
\hline $\begin{array}{l}\text { Cheng et } \\
\text { al (39) }\end{array}$ & 2013 & $\begin{array}{ll}51 & \\
\text { pediatrics } \\
\text { (30 } & \mathrm{HL} \\
\text { and } & 21 \\
\mathrm{NHL} & \end{array}$ & NA & NA & NA & NA & NA & NA & NA & NA \\
\hline $\begin{array}{l}\text { London K } \\
\text { et al (40) }\end{array}$ & 2011 & $\begin{array}{l}71 \\
\text { pediatrics }\end{array}$ & $95.9 \%$ & $99.7 \%$ & - & & $70.1 \%$ & $99 \%$ & - & - \\
\hline
\end{tabular}

HL: Hodgkin lymphoma; NHL: non-Hodgkin lymphoma; NA: not available; NPV: negative predictive value; PPV: positive predictive value 

